\title{
Geotechnical investigation of landslide near Sairang Village in Aizawl district, Mizoram, India
}

\author{
H. Lawmkima \\ Department of Geology, Pachhunga University College, Aizawl 796001, Mizoram, India \\ Corresponding author: h.lawmkima@gmail.com
}

\begin{abstract}
The investigated landslide area is about $5.4 \mathrm{~km}$ north of Sairang village on Aizawl-Silchar road (NH-54). The length, breadth and height of slide are $110 \mathrm{~m}, 20 \mathrm{~m}$ and $70 \mathrm{~m}$ respectively. The dominant rock types exposed in the study area are sandstone, siltstone and shales and their admixtures in various proportions. The main factors for the instability of this area stems from the intersection of two sets of joints dividing the rock beds into varying dimensions and the presence of bedding shears and clay pockets/beds with swelling and shrinkage properties, decrease in the shear strength of overburden and bed rocks during rainy season due to water saturation and erosion of shaly layer by scouring action and a high hill slope. Remedial measures such as; lined catch water drains and chute for channeling surface water flow along the hill slope; lining of side drain to prevent toe erosion and also to prevent water percolation through debris. Sealing/filling of ground fractures/cracks with clayey material; breast and retaining structures to prevent toe erosion are suggested.
\end{abstract}

Keywords: Landslide, Sairang, sandstone, silty-shale, joints, drainage.

\section{INTRODUCTION}

There was recurrent landslide near Sairang village, Aizawl district in Mizoram. It covers an area (Lat $23^{\circ}$ $50^{\prime} 27^{\prime \prime} \mathrm{N}$ and Long $92^{\circ} 40^{\prime} 15^{\prime \prime} \mathrm{N}$ ) is located at about 27.4 $\mathrm{km}$ from Aizawl, the capital city of Mizoram, on AizawlSilchar road (about $5.4 \mathrm{~km}$ north of Sairang village). It lies at the junction of western aspect of a N-S trending hill range and a E-W trending spur. National Highway (NH 54) passes through the middle of the hill and a small bridge has been constructed over a culvert that intersects the slide area at the middle. The left half of the area is covered with thick vegetation whereas right one is devoid of vegetation.

The length, breadth and height of slide are $110 \mathrm{~m}, 20$ $\mathrm{m}$ and $70 \mathrm{~m}$ respectively. The material involved in the sliding are debris and small and large blocks of rocks. The supply of the material is from the 1-2 m thick overburden and $125 \mathrm{~m}$ high slope face composed of highly weathered and jointed rocks (Figures 1 and 2).

\section{MATERIALS AND MethodS}

A detailed geological fieldwork in the landslide area was carried out with the help of Brunton compass, handheld GPS, toposheet and other geological equipment. During the field work, numbers of attitude of rock discontinuities such as joint sets, rock bedding and joint spacing etc. were recorded. These field data are plotted to identify the joint sets using GEOrient software. Measurements and readings of the dominant rock types were taken for the calculation of the factor of safety of the slope materials in the slide area using the factor of safety formula (Neman et al., 2017). On Analysis of these information the causes of instability were chalked out and remedial measures was suggested for the area under study.

\section{Geology of the area}

The study area lies in the western limb of Aizawl anticline. The rocks exposed in the area belong to upper unit of Bhuban Formation of Surma Group (Tiwari and Kumar, 1995). The dominant rock types exposed in the study area are sandstone, siltstone and shales and their admixtures in various proportions. The general trend of rock formations is N-S with $40^{\circ}$ dip due west. The rocks are intersected by two sets of joints besides a bedding plane 
Figure 1: Synoptic view of the study site.

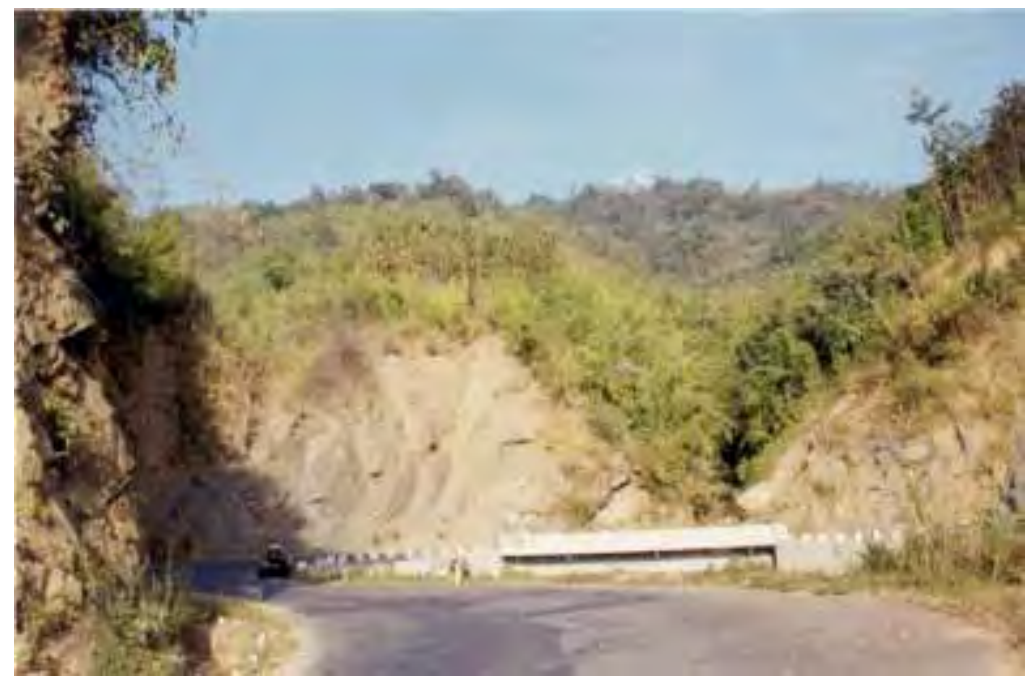

Figure 2: Close view of the crown area of the study site.

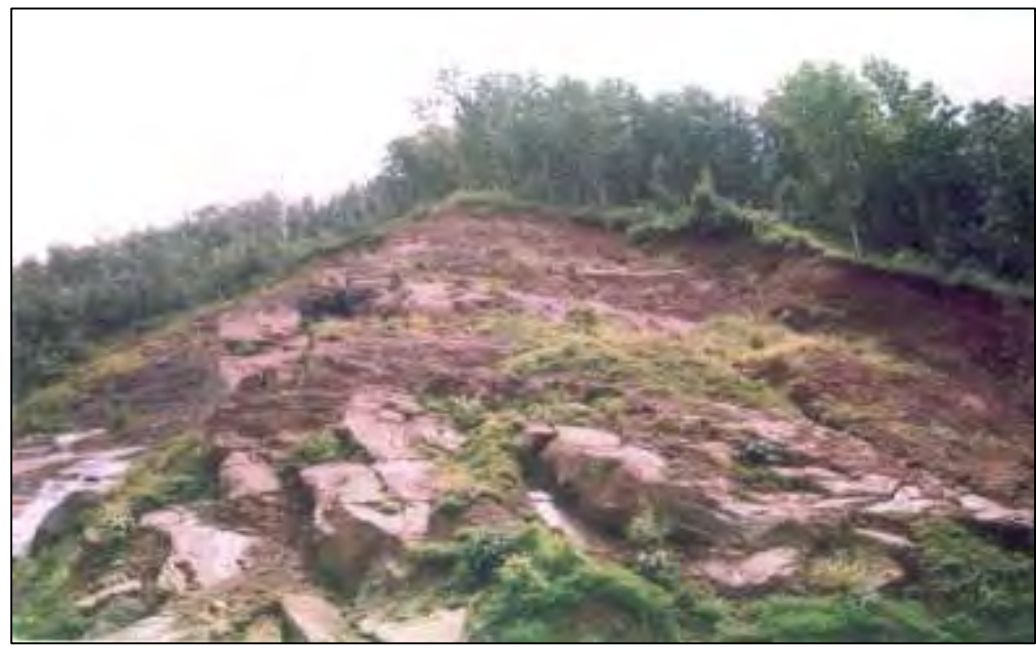

joints. Five litho-units have been delineated in the slide area (Table 1). The lithological map of the study was prepared as shown in Figure 3. The details of the rock types and bed thickness are as follows:

\section{Kinematic study of rock discontinuities}

Analysis of slope stability is a complex and cumbersome exercise because there are many rock discontinuities in a rock mass such as bedding planes, joint planes and fissures. Majority of the slip surfaces of the landslides are influenced by the orientation, spacing and nature of the surfaces of the rock discontinuities, and their relation to the slope (Piteau, 1970). The shear strength of rock mass and its deformability are also influenced by the pattern, geometry and extent of development of rock discontinuities. The rock mass strength is affected by spacing of the rock discontinuities to the extent that even strong intact rock can be reduced to the weak ones if intersected by closely spaced several joint sets.

Orientation and frequency of rock discontinuities jointly influence the response of a rock mass to the slope failure. Closely spaced joint planes tend to cause massive block failure. Kinematic analysis of joint plane is therefore necessary in order to understand their influence in the overall instability of slope. Though, kinematic analysis of rock discontinuities does not provide the numerical measure of the degree of instability of the slope, it provides the information whether or not the stability of slope is feasible. The two primary factors that help determine the influence of orientation of joint planes on the stability of slopes are:

- Whether joint or joint intersection cut the slope at angle less than the angle of natural or manmade slope, and if so,

- Whether the dip angles of the joints or the angle of plunge of the joints

- Intersections exceed the angle of friction along the joint surface.

The methodology of the kinematic analysis of rock discontinuities involves:

- Measurement of attitude of maximum numbers of rock discontinuities

- Plotting of the readings of the stereonet 
Table 1: Details of the litho-units in the study area.

\begin{tabular}{|c|l|c|l|}
\hline Bed No. & \multicolumn{1}{|c|}{ Lithology } & Thickness $(\mathbf{m})$ & \multicolumn{1}{c|}{ Description } \\
\hline 5 & Silty Shale & 3.6 & Brown coloured, medium bedded, fine grained. \\
\hline 4 & Sandstone & 5.0 & $\begin{array}{l}\text { Thickly bedded, brown coloured and fined grained. Spacing of bedding } \\
\text { planes and joint sets are nearly 2m. }\end{array}$ \\
\hline 3 & Intraformational & 0.5 & Grey coloured, hard and bioturbated conglomerates. \\
\hline 2 & Shale & 5.5 & $\begin{array}{l}\text { Deep grey coloured, thinly bedded and crumpled, very fine grained and } \\
\text { smooth, occasionally clayey and micro-cross laminated. }\end{array}$ \\
\hline 1 & Sandstone-shale & 22.5 & $\begin{array}{l}\text { Sandstone is brown, fine grained, silty alternation and rippled, Shale } \\
\text { is grey coloured, micaceous and laminated. }\end{array}$ \\
\hline
\end{tabular}

- Determination of main discontinuity sets, and

- Determination of possible mode of failure

About 75 readings of joint sets from the study site were recorded with the help of Brunton Compass. These were plotted in the Stereonet using GEOrient software. Three joint sets have been identified from the contour diagrams of (Figures 4(a),(b),(c)) of these joint poles. These joint sets were plotted in the stereonet along with the slope angles. Three wedges in the stereoplot of Sairang landslide (Figure 4(d)) have been identified. Rose diagram of joint sets has also been prepared to show the frequency of occurrence of joints (Figure 4(e)). The atti-

Table 2: Attitudes of joint sets and wedges.

\begin{tabular}{|ll|lc|}
\hline \multicolumn{2}{|c|}{ Orientations of joint sets } & \multicolumn{2}{c|}{ Orientations of Wedges } \\
\hline $\mathrm{J} 1=\mathrm{SO}$ & $37^{\circ} / 274^{\circ}$ & $\mathrm{W} 1$ & $15^{\circ} / 210^{\circ}$ \\
\hline $\mathrm{J} 2$ & $70^{\circ} / 128^{\circ}$ & $\mathrm{W} 2$ & $50^{\circ} / 070^{\circ}$ \\
\hline $\mathrm{J} 3$ & $60^{\circ} / 058^{\circ}$ & $\mathrm{W} 3$ & $20^{\circ} / 330^{\circ}$ \\
\hline Slope & $50^{\circ} / 270^{\circ}$ & \multicolumn{2}{|c}{} \\
\hline \multicolumn{2}{|c|}{} \\
\hline \multicolumn{2}{|c|}{}
\end{tabular}

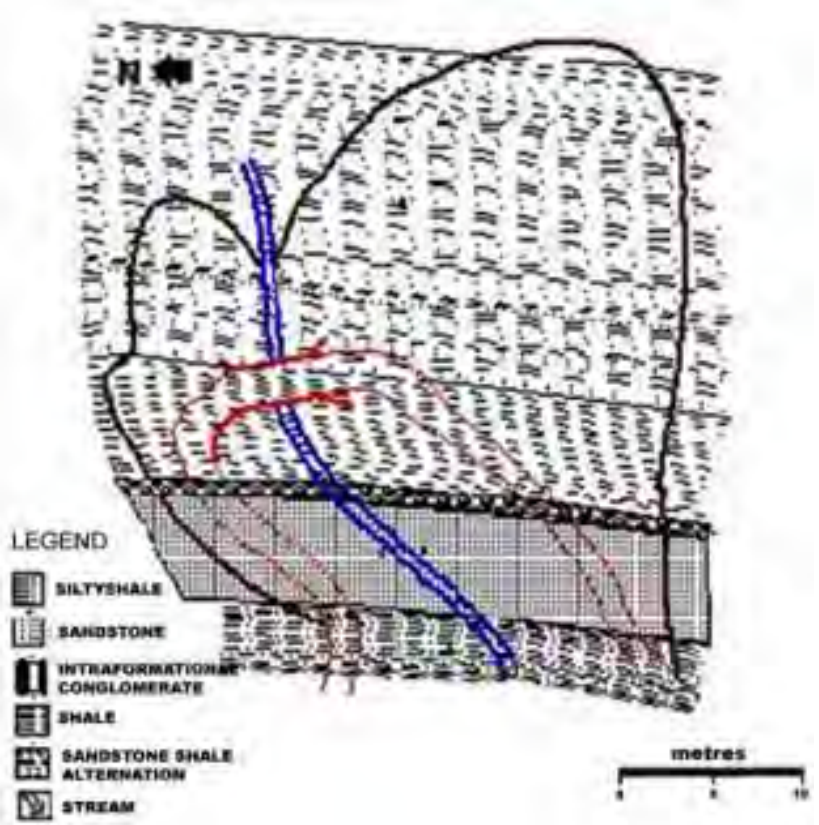

Figure 3: Lithological map of the landslide area.

tudes of joint sets and of the wedges are as in Table 2.

The spacing of $\mathrm{J} 2$ and $\mathrm{J} 3$ at the slided area is $1.6 \mathrm{~m}$ and $1 \mathrm{~m}$ respectively. The joint openings of $\mathrm{J} 2$ and $\mathrm{J} 3$ are 3-5 $\mathrm{mm}$ and 2-3mm respectively. The joint surfaces of $\mathrm{J} 2$ and $\mathrm{J} 3$ are rough and rippled respectively. The stereo plot indicates planar failure because it is along the prevalent and continuous joint set (J1) dipping towards the slope (Romana, 1985). Moreover, the strike of this joint set is near parallel to the dip of the slope face and dip is less than the dip of the slope. Thus, joint set J1 (=SO) is most critical for the stability of the slope. W1 is formed by the intersection of $\mathrm{J} 1$ and $\mathrm{J} 2, \mathrm{~W} 2$ by the intersection of $\mathrm{J} 2$ and $\mathrm{J} 3$ and $\mathrm{W} 3$ by $\mathrm{J} 1$ and $\mathrm{J} 3$.

\section{Factor of safety}

The factor of safety was calculated using the limit equilibrium method with the following formula:

Factor of safety $(F S)=\underline{C A+W \operatorname{Cos} \alpha \operatorname{Tan} \Phi}$ W $\operatorname{Sin} \alpha$

Where

C = Cohesive strength,

A = Total area of failure surface,

$\mathrm{W}=$ Total weight of the failed mass

$\alpha \quad=$ Angle of failure plane

$\phi \quad=$ Angle of friction of the failure surface

\section{Sample-1: Sandstone (of the study site)}

Height ( $h$ )

Total area of failure surface (A)

Average density of rock mass (D)

Total weight of slided mass (W)

Cohesion strength of failure plane $(C)$

Angle of friction of the failure $(\alpha)$

$\operatorname{Cos} \alpha$

$\operatorname{Tan} \phi$

$\operatorname{Sin} \alpha$

By putting above values in the equation, we get

$\mathrm{FS}=\underline{5 \times 10^{5} \times 101.25+253125 \times 10^{2} \times 0.695 \times 0.213}$

$$
253125 \times 10^{2} \times 0.719
$$

$\mathrm{FS}=\underline{11241407.8125}$

18199687.50

$\mathrm{FS}=0.62$
: $22.5 \mathrm{~m}$

: $101.25 \mathrm{~m}^{2}$

: $2500 \mathrm{Kg} / \mathrm{m}^{2}$

: $253125 \times 10^{2} \mathrm{Kg}$

: $5 \times 10^{5} \mathrm{~Pa}$

: $46^{\circ}$

: 0.695

: 0.213

: 0.719 


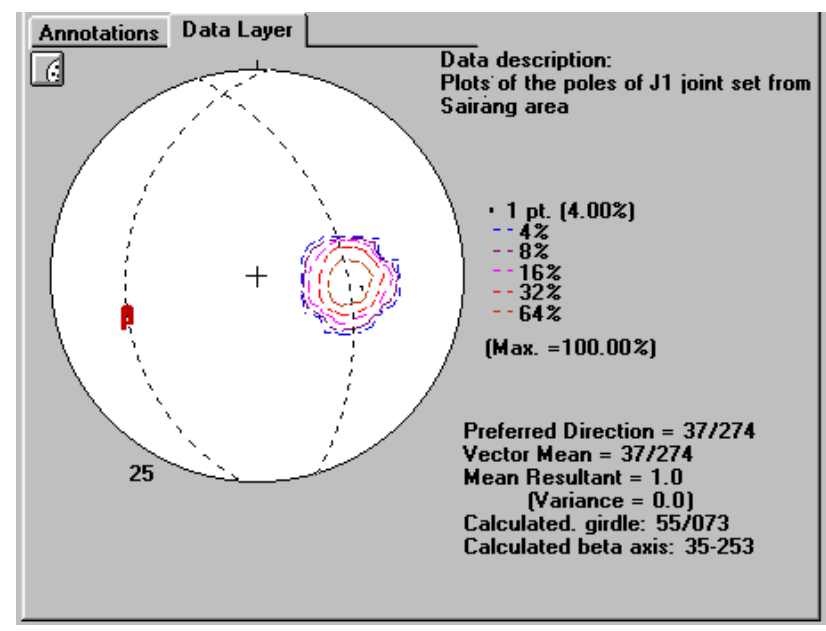

Figure 4(a): Plots of the poles of J1 joint set from study area.

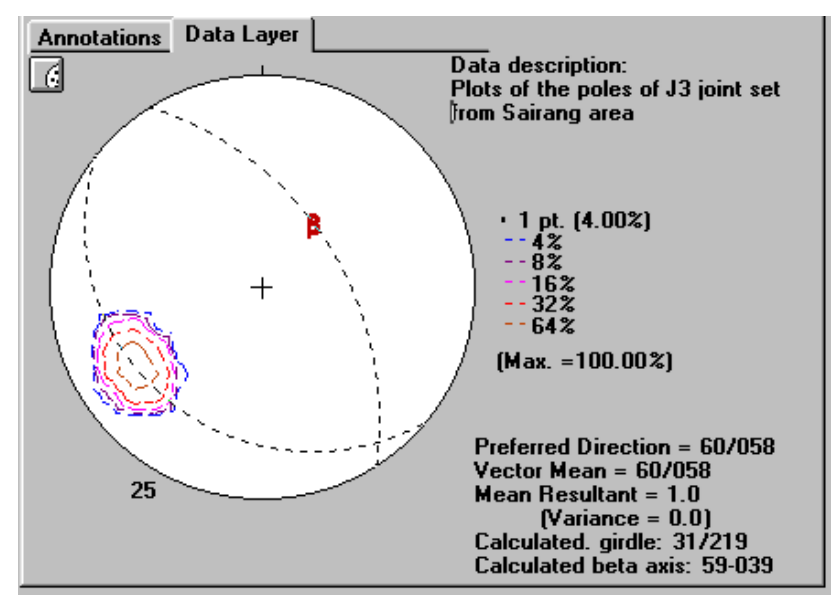

Figure 4(c): Plots of the poles of J3 joint set from study area.

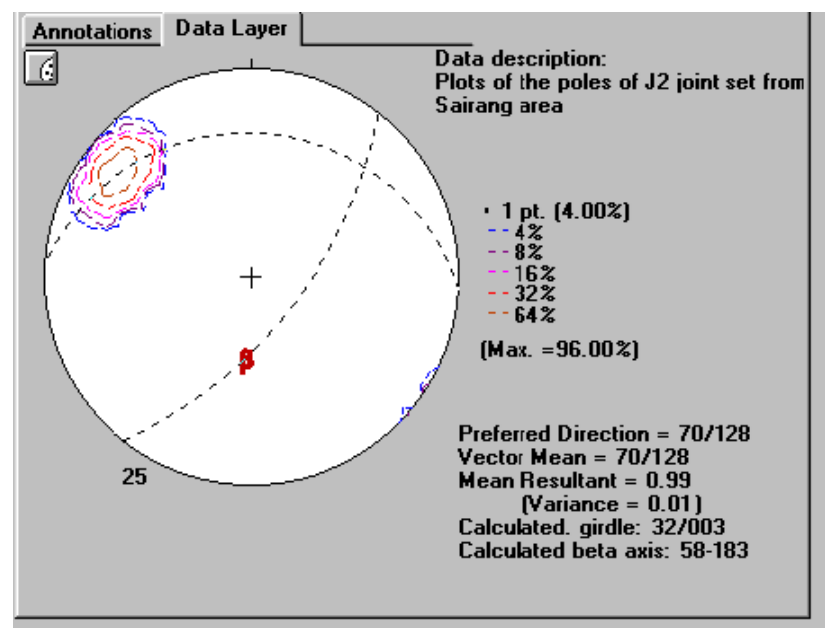

Figure 4(b): Plots of the poles of $\mathrm{J} 2$ joint set from study area.

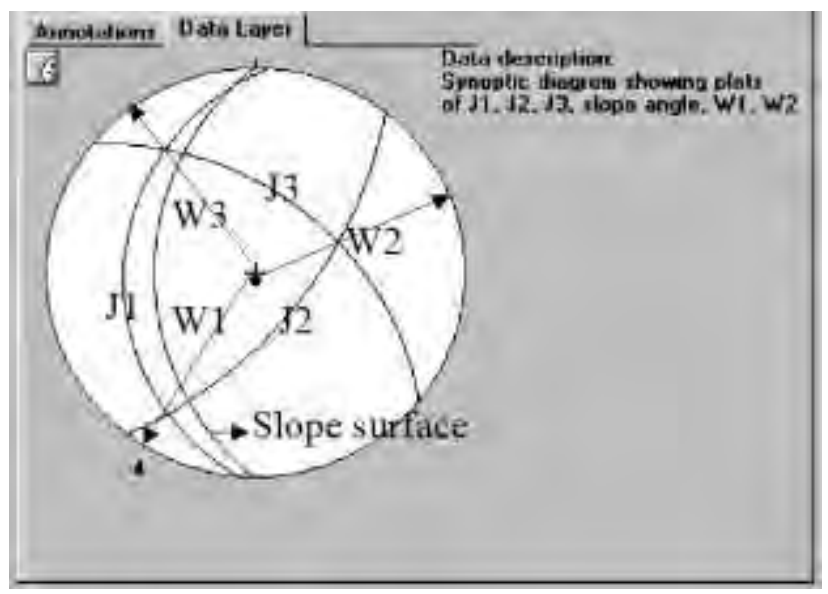

Figure 4(d): Synoptic diagram showing plots of J2, J3, slope angle, W1, W2.

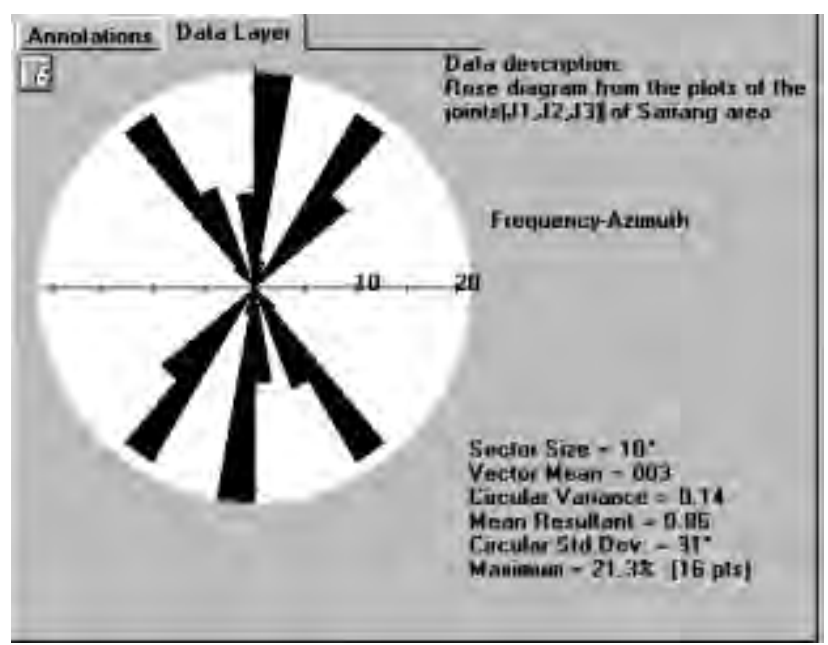

Figure 4(e): Rose diagram from the plots of the joints $(\mathrm{J} 1, \mathrm{~J} 2, \mathrm{~J} 3)$ of Study area. 


\section{Sample-2: Shale (of the study site)}

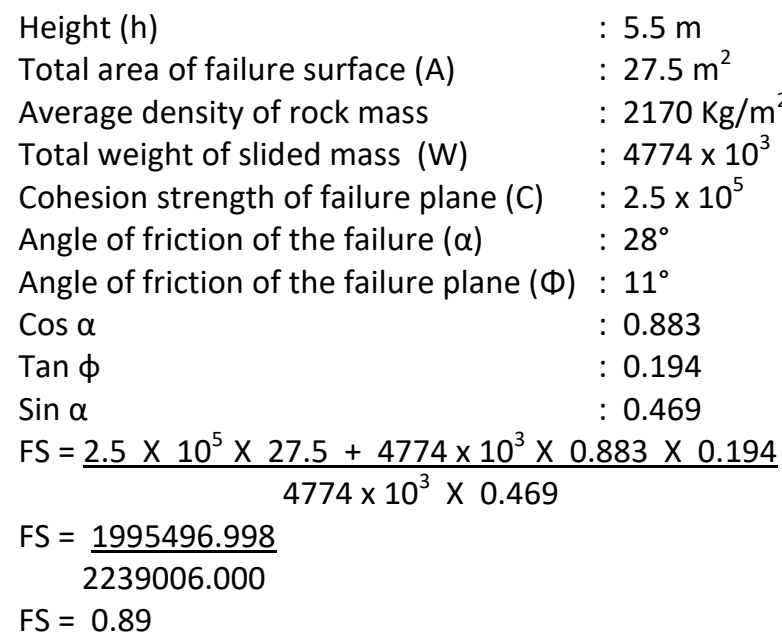

Factor of safety for sandstone is 0.62 , which is less than that of shale, i.e. 0.89 . This can be understood by the several factors. Among which most conspicuous one is the fact that slope height at the sandstone horizon $(22.5 \mathrm{~m})$ is considerably higher than height at shale horizon $(5.5 \mathrm{~m})$. Despite the fact that average cohesion of sandstone horizon which is $5 \times 105 \mathrm{~Pa}$, is double than that of shale horizon, the slope at sandstone site is more vulnerable than Shale site.

\section{RESULTS}

\section{Causes of landslide}

After carefully studying the slide, it is inferred that the present slide was due the following causes:

1. Presence of bedding shears and clay pockets/beds with swelling and shrinkage properties. This in conjunction with the poor shear strength of the slope forming material both in natural moisture content caused frequent slope failure at this locality. Further, decrease in the shear strength of overburden and bed rocks during rainy season due to water saturation also contributed significantly to the frequent failure of slope at this point.

2. Frequent lithological variations lead to frequent change in the stability conditions. Factor of safety worked out at two points in two litho-units (i.e. sandstone and shale) is 0.62 and 0.89 respectively.

3. Steep hill slope at the crown part of the slide led to failure at the crown. This lead to sliding of soil debris and even bed rock as the thickness of the soil is thin at the crown.

4. Removal of shaley horizons by scouring action during heavy rains. This loosens the blocks of sandstones (formed by intersections of joint planes and bedding plane) that slided down the slope.

5. The stereo plot of joint sets indicates planar failure because it is along the prevalent and continuous joint set (J1) dipping towards the slope. Moreover, the strike of this joint set is near parallel to the dip of the slope face and dip is less than the dip of the slope. Thus, joint set J1 (=SO) is most critical for the stability of the slope.

6. Slope forming materials are not self-draining and thereby a hydrostatic pressure is developed that is detrimental to the slope stability.

\section{Remedial measures}

From the above results on the geotechnical investigations of the landslide, the following remedial measures may be suggested to the slope failure:

1. Provision for suitably lined catch water drains of adequate capacity sloping towards hill with chute for channeling surface water flow from slide zone. There should be provision for deep drains to minimize saturation of debris material.

2. Lining of side drain that is formed at the middle of the slide zone to keep free flowing condition, to prevent toe erosion and also to prevent water percolation through debris.

3. Sealing/filling of ground fractures/cracks with clayey material in order to prevent percolation of water and depth of zone saturation of slope material. This in turn will prevent reduction in the shearing strength of slope material.

4. Checking of toe erosion by providing suitably designed breast and retaining structures as a guard against toe erosion.

5. Provision of boulder crate to prevent toe erosion.

6. Provision of wooden piles at suitable intervals to check debris flow.

7. Afforestation in the slide mass using fast growing trees and grasses.

\section{REFERENCES}

Aleotti, P., Chowdhury, R. (1999). Landslide hazard assessment: summary review and new perspectives. Bulletin of Engineering Geology and the environment, 58(1), 21-44.

Anbalagan, R. (1992). Landslide hazard evaluation and zonation mapping in mountainous terrain. Engineering Geology, 32(4), 269-277.

Choubey, V.D., Lallenmawia, H. (1987): Landslides and other mass movement in Aizawl, Mizoram State, North-east India. Proceedings of the $5^{\text {th }}$ International Conference and Field Workshop on Landslide, pp. 113120.

Coates, D.R. (1977). Landslide perspective. In: D.R. Coates (Editor), Reviews in Engineering Geology: Landslides. Geological Society of America, Colorado, USA, pp. 3-28.

Ganguly, S. (1974). Note on the structures and tectonics 
of Mizoram. Proceedings of the $61^{\text {st }}$ Indian Science Congress Association, Pt. iii, p. 132 (Abs).

Goodman, R.E. (1976). Methods of Geological Engineering in Discontinuous Rocks. St. Paul: West Publisher.

Guzzetti, F., Carrara, A., Cardinalli, M., Reichenbach, P. (1999). Landsldie hazard evaluation: A review of current techniques and their application in a multi-scale study, Central Italy. Geomorphology 31, 181-216.

Nandy, D.R. (2000). Geodynamics of Northeastern India and the Adjoining Region. ACB Publication, pp. 1-183

Neman, N., Zakaria, Z., Sophian, R. I., Adriansyah, Y. (2018, April). Probability of failure and slope safety factors based on geological structure of plane failure on Open Pit Batu Hijau Nusa Tenggara Barat. IOP Conference Series: Earth and Environmental Science 145, 012077.

Piteau, D.R. (1970). Geological factors significant to the stability of the slope cut in rocks. Proceedings of the
Symposium on Planning Open Pit Mines, Johannesburg, South Africa, pp. 33-53.

Romana, M. (1985). New adjustment ratings for application of Bieniawski classification to slopes. Proceedings of the International Symposium on Role of Rock M echanics, Zacatecas, Mexico, pp. 49-53.

Sreekumar, S. (2009). Techniques for slope stability analysis: Site specific studies from Idukki district, Kerala. Journal of the Geological Society of India, 73(6), 813-820.

Tiwari, R.P., Sharma, B.L., Singh, B. (1996a). Geotechnical appraisal of Bawngkawn landslide, Aizawl, Mizoram. Proceeding of International Conference on Disaster and M itigation, Madras, India, 1, -A4 124-A4 131.

Tiwari, R.P. and Kumar, S. (1997). South Hlimen landslide in Mizoram- A pointer. Envis Bulletin, 5(2), 12-13.

Zaruba, Q., Mencl, V. (1982). Landslide and Their Control. Elsevier Scientific Publication Company, London, $p$. 324. 